\title{
An Experimental Investigation to Examine the Wicking Properties of Silk Fabrics
}

\author{
Md Kamrul Hasan, Juramirza Kayumov, Guocheng Zhu, Munna Khatun, Asaduzzaman Nur, \\ Xinbo Ding*
}

School of Materials and Textile, Zhejiang Sci-Tech University, Hangzhou, China

Email: ^dxblt@zstu.edu.cn

How to cite this paper: Hasan, M.K., Kayumov, J., Zhu, G.C., Khatun, M., Nur, A. and Ding, X.B. (2019) An Experimental Investigation to Examine the Wicking Properties of Silk Fabrics. Journal of Textile Science and Technology, 5, 108-124.

https://doi.org/10.4236/jtst.2019.54010

Received: October 11, 2019

Accepted: November 3, 2019

Published: November 6, 2019

Copyright $\odot 2019$ by author(s) and Scientific Research Publishing Inc. This work is licensed under the Creative Commons Attribution International License (CC BY 4.0).

http://creativecommons.org/licenses/by/4.0/

\begin{abstract}
In this research, the wicking characteristics of fabrics were used as an essential and effective indicator to investigate the satisfaction of heat and moisture. Due to the popularization of silk fabrics recently it has become an interesting topic to know about the wicking behavior of silk fabrics in water. The absorptive capability of the silk textile makes clothing comfortable even for a hotter environment. Silk fabrics are comfortable in the summer, and warm in the winter. Silk fabric can usually contain about 11 percent of its weight in moisture but the range varies from $10 \%$ to as much as $30 \%$. In this paper, the wicking behavior of silk fabric in both warp and weft directions was investigated in terms of wicking height, wicking rate, mass increase distribution per centimeter of wicking height, the velocity of wicking height, and durability of wicking height after removal of the wicking liquid reservoir. The experimental results show that the wicking height in both the warp and weft directions had a good correlation with the time. The wicking rate was comparable in both weft and warp directions, but at the start of the wicking phase, weft direction wicking was quicker than warp direction. The mass increase in fabric per centimeter of wicking height was inversely proportional to wicking height. The mass of moisture carried in the fabric did not significantly differ in the direction of the weft and warp.
\end{abstract}

\section{Keywords}

Silk Fabric, Wicking Behavior, Warp and Weft Direction, Rate of Wicking, Velocity of Wicking, Durative Wicking Height, Contact Angle

\section{Introduction}

Due to the popularization of silk fabrics recently it is interesting to know about the wicking behavior of silk fabrics in water. Silk fabric manufacturers are claim- 
ing consumer's great physiological comfort. This comfort is said to be the ability to absorb moisture from the skin and it keeps the consumer dry [1]. Recently people are very interested in comfort clothing because silk fabric not only has an aesthetic appearance but also provides an excellent feeling. Fabrics are used to make clothes that are directly connected to the human body and interact with the skin during use [2]. For this reason, people always prefer comfortable and fashionable clothes. Natural silk fabrics are already widely used as textiles due to their reliable cost, comfort and convenience merits [3]. The absorptive capability of the silk textile makes clothing comfortable with a good aesthetic appearance even for a hotter environment. The first option for the consumer to purchase a dress is a cloth that is comfortable and capable of wicking well. Silk fabrics are comfortable in the summer, and warm in the winter, as it can usually contain good percent of its weight in moisture [4]. Some experiments depending on the wicking height, weight, rate, velocity, and contact angle to determine the wicking behavior of silk fabric. All of these give a concept of wicking ability as part of studying the movement of water through the silk fabric. Generally accepted moisture transport in textiles is one of the critical factors affecting physiological comfort, particularly for silk sportsmen sportswear, silk underwear and sports silk garments [5] [6] [7]. When people move and sweat, clothing absorbs and transfers the moisture outside due to the difference in concentration of liquid molecules and the difference in pressure on both sides of the cloth. Most people would feel uncomfortable when there is more moisture, sweat, and unexpectedness than the clothes' absorption capacity [8]. The clothes cannot transfer the entire moisture outside within a short period of time, due to the fabric's limited capacity for absorption and limited capacity for moisture transfer. By understanding the liquid transportation mechanism, the comfort given by textiles can be improved. Wicking is the easy transportation of a liquid driven into a porous system by a capillary force [9], which has often been used in textiles, to express the moisture transport in textiles. Some researchers have discussed capillary behaviors, similar to the behavior of wicking. The Lucas-Washburn equation [10] [11] was used to describe the capillary behaviors in cylindrical tubes, the capillary penetration rate depends on the properties of the liquid such as the capillary spaces' surface tension, viscosity, density, and geometry. In response to the various stimuli, including temperature, moisture, suddenness, light, $\mathrm{pH}$, etc., driven by the fiber volume expansion mechanism [8], the fiber of silk fabric can provide large-angle torsional actuation and giant tensile actuation. Silk fibers caused a $70 \%$ contraction when relative humidity (RH) was changed from $20 \%$ to $80 \%$, which was larger than that of a coiled CNT yarn driven by organic solvents (60\%) [8]. Lucas-Washburn equation has been widely used to evaluate the wicking behavior in porous materials, yarns and fabric [12] [13] [14] [15] [16]. The movement of liquid in the void spacing between fibers in a yarn has a critical impact on the fabric wicking mechanism [17] reported by Rajagopalan, which is discussed about wicking behavior. Much larger pores between yarns do not contribute significantly to liquid's long-range movement based on capillary laws [8]. 
Minor [18] reported that intersections of yarn act as new reservoirs and feed equally all branches. Hollies [19] alleged that the fiber arrangement in yarns, which controls the capillary size and continuity, governs the rate of liquid movement. In another literature, Saricam [20] also stated that on the wicking performance, the weft density, pore size and the arrangement of void spaces in fabric had a high imbalance pact. In the theoretical task of analyzing the wicking properties of textiles were mainly focused on four forces; there is a capillary force, gravity, viscous drag, and inertia [13] [21]. The transformation of liquid into fabrics is more complicated than the difficulty of determining the effective radius of the capillary and the effective contact angle due to its nature and structure [13]. Harnett and Mehta [22] have assimilated several wicking measurement laboratory testing methods. They said that measuring the wicking heights in different fabrics only gives some indication of the liquid front rate and would be more valuable if linked to the mass transfer rates. In this situation, due to the liquid absorption of textiles, the mass gradient of liquid in textiles allows the movement of liquid.

This paper examines the wicking direction of warp \& weft direction and more detailed information about silk fabric wicking behavior. After removal of the wicking liquid reservoir, the wicking property of silk fabric was studied in terms of wicking height, wicking rate, wicking weight, wicking velocity and durable wicking height. A common method was used to assess wicking behavior, wicking velocity, wicking percentage, and silk fabric contact angle.

\section{Material and Experimental}

For this experimental work, five $100 \%$ silk fabric samples were used, which were different construction and different types of silk fabrics. The silk fabrics are Chiffon silk fabric, Crepe de Chine silk fabric $16 \mathrm{~mm}, 12 \mathrm{~mm}, 14 \mathrm{~mm}$, and Taffeta silk. The specifications of silk fabric are given in Table 1, and the surface morphology of silk fabric is shown in Figure 1. Initially, the silk fabrics were placed in an incubator for $24 \mathrm{~h}$ at a temperature of $35^{\circ} \mathrm{C}$, and then the temperature of the incubator was lowered to $15^{\circ} \mathrm{C}$ for $24 \mathrm{~h}$. After cooling, the dry relaxed silk fabrics were used for testing. Samples were clapped vertically and then partially immersed in a liquid reservoir. The weights of silk fabrics before and after

Table 1. Specifications of silk fabrics.

\begin{tabular}{|c|c|c|c|c|c|c|}
\hline \multirow{2}{*}{ Samples } & \multicolumn{2}{|c|}{ Yarn diameter $(\mathrm{mm})$} & \multirow{2}{*}{$\begin{array}{l}\text { Surface mass } \\
\qquad\left(\mathrm{g} / \mathrm{m}^{2}\right)\end{array}$} & \multicolumn{2}{|c|}{$\begin{array}{l}\text { Thread density num- } \\
\text { ber } / 10 \mathrm{~cm}\end{array}$} & \multirow{2}{*}{ Thickness (mm) } \\
\hline & Warp & Weft & & Warp & Weft & \\
\hline $\mathrm{A}$ & $0.10 \pm 0.01$ & $0.10 \pm 0.01$ & $97 \pm 1$ & $452 \pm 3$ & $389 \pm 3$ & $0.346 \pm 0.01$ \\
\hline B & $0.08 \pm 0.01$ & $0.10 \pm 0.01$ & $57 \pm 1$ & $660 \pm 5$ & $397 \pm 3$ & $0.175 \pm 0.01$ \\
\hline C & $0.09 \pm 0.01$ & $0.10 \pm 0.01$ & $55 \pm 1$ & $626 \pm 5$ & $387 \pm 3$ & $0.174 \pm 0.01$ \\
\hline $\mathrm{D}$ & $0.05 \pm 0.01$ & $0.11 \pm 0.01$ & $56 \pm 1$ & $587 \pm 3$ & $413 \pm 3$ & $0.195 \pm 0.01$ \\
\hline E & $0.07 \pm 0.01$ & $0.07 \pm 0.01$ & $71 \pm 1$ & $1068 \pm 5$ & $511 \pm 5$ & $0.178 \pm 0.01$ \\
\hline
\end{tabular}


wicking were recorded and the wicking height measured. A model of the testing apparatus is shown in Figure 2.

The sample size was $5 \mathrm{~cm} \times 20 \mathrm{~cm}$, the temperature of water $15^{\circ} \mathrm{C}$ and in this water added some different color for clearly understanding the wicking. The immersion depth of the fabric in water was $2 \mathrm{~cm}$. Measurement of the experimental data was carried out by the following two methods:

1) Measurement of the wicking height, weight of fabric before and after wicking, and time every $1 \mathrm{~cm}$ of the wicking height;

2) Fabric samples were removed from the distilled water when the wicking height reached $1 \mathrm{~cm}, 2 \mathrm{~cm}, 3 \mathrm{~cm}, 4 \mathrm{~cm}$ and $5 \mathrm{~cm}$, respectively. And then the final durative wicking height was recorded.

Each group of samples was tested five times and the average value calculated.

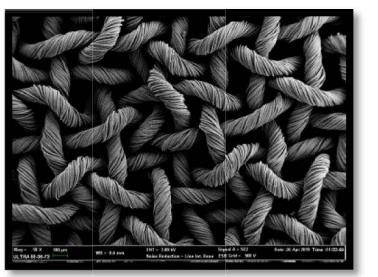

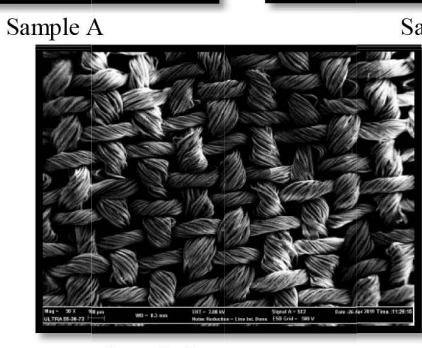

Sample D

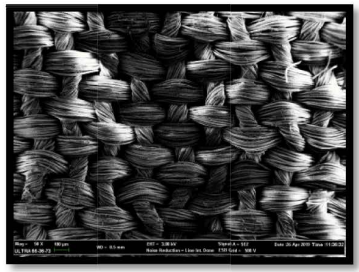

Sample B

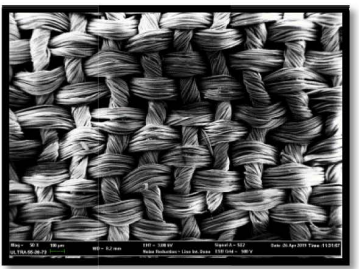

Sample C

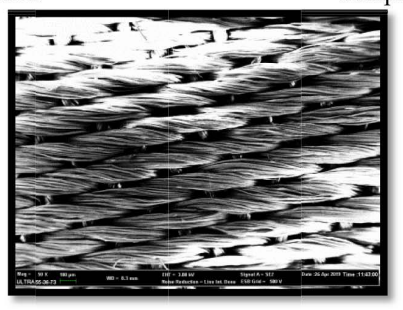

Sample E

Figure 1. Surface morphology.

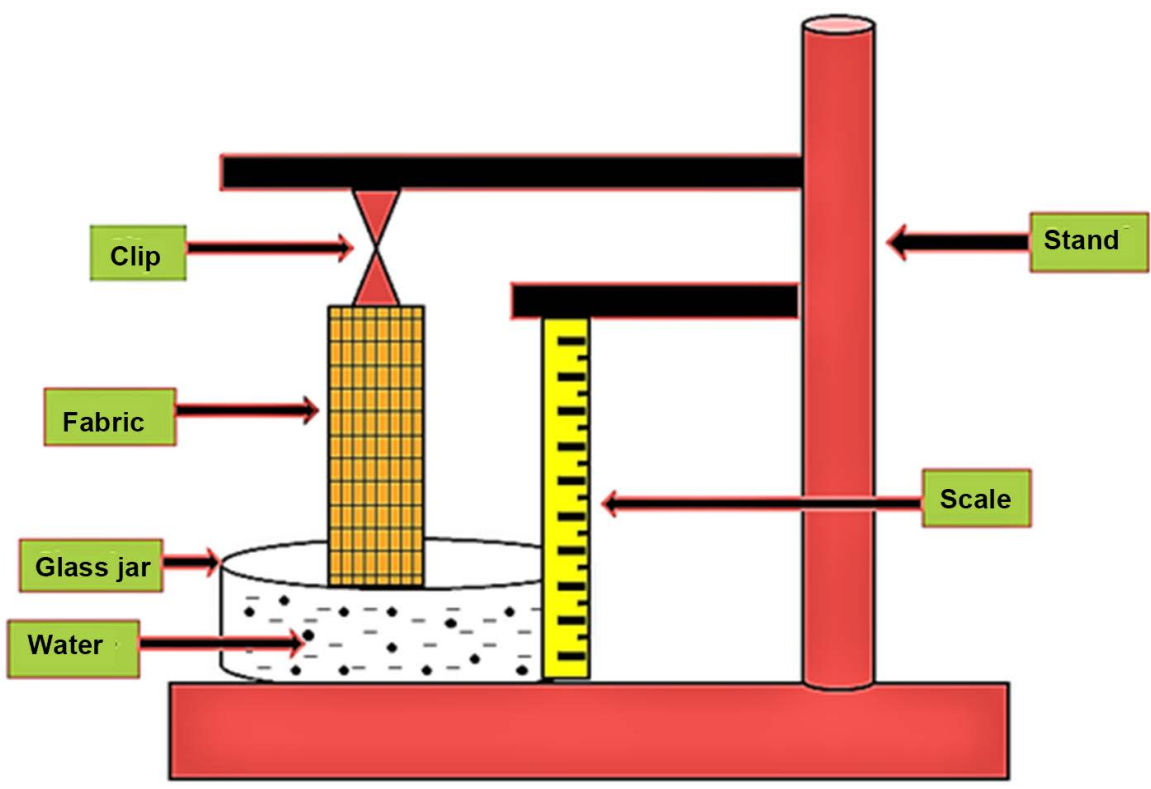

Figure 2. Testing apparatus. 
The above surface morphology pictures, the horizontal lines are indicated the warp yarn direction and the vertical lines are indicated the weft yarn direction (Figure 1).

\section{Result and Discussion}

Silk fabric can usually contain about 11 percent of its weight in moisture but the range varies from $10 \%$ to as much as $30 \%$. Water molecules can be easily absorbed into silk fibroin because of the high density of hydrophilic groups and nanopores in the silk fiber. The silk fiber increased volume by about $34 \%$ and diameter by about $15 \%$ at maximum water absorption, but increased length by only about $1 \%[5]$.

Pore dimensions calculation:

Total yarn space $(\mathrm{cm})=$ Thread density $\times($ Yarn diameter $\div 10)$

Total gap space $(\mathrm{cm})=$ Fabric length - Total yarn space

Pore dimensions $(\mathrm{mm})=($ Total gap space $\div$ Thread density $) \times 10$

Table 2. The pore dimensions in the fabric.

\begin{tabular}{ccc}
\hline Sample & Warp pore dimensions & Weft pore dimensions \\
\hline A & $0.124 \pm 0.001 \mathrm{~mm}$ & $0.157 \pm 0.001 \mathrm{~mm}$ \\
B & $0.072 \pm 0.001 \mathrm{~mm}$ & $0.158 \pm 0.001 \mathrm{~mm}$ \\
C & $0.070 \pm 0.001 \mathrm{~mm}$ & $0.158 \pm 0.001 \mathrm{~mm}$ \\
D & $0.120 \pm 0.001 \mathrm{~mm}$ & $0.132 \pm 0.001 \mathrm{~mm}$ \\
E & $0.024 \pm 0.001 \mathrm{~mm}$ & $0.126 \pm 0.001 \mathrm{~mm}$ \\
\hline
\end{tabular}

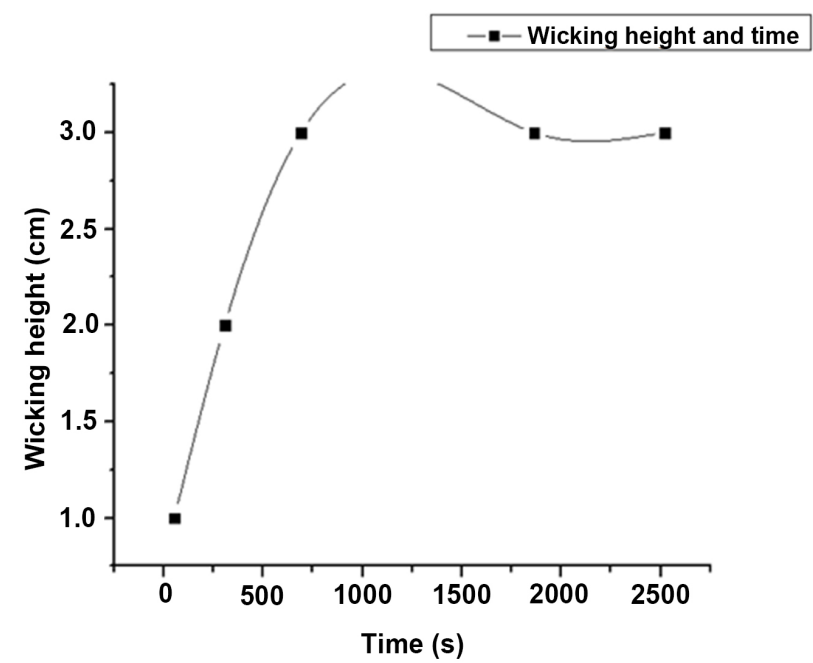

Figure 3. The wicking height of sample A.

Sample A's wicking ability is less from others. Due to this fabric surface construction and the pore size of this fabric, it takes too much time to reach the test distance. Figure 3 shows the time axis is $52 \mathrm{sec}$ then the wicking height axis is 1 
$\mathrm{cm}$. Thus, when the time axis is 306, 690, 1864 and $2520 \mathrm{sec}$, then the wicking height axis is 2, 3, 3 and $3 \mathrm{~cm}$. After $3 \mathrm{~cm}$ of height, the wicking has stopped. The sample A's wicking velocity is slightly good at the beginning, but after a few seconds later wicking velocity decreased and when the wicking height reached 3 $\mathrm{cm}$ then the wicking is completely stopped. Sample A's surface construction is different; it looks like wave curve weaving silk fabric. Both warp yarn and weft yarn in this fabric are twisted and a little tight and look like weaving structures with a slight loss. This fabric warp pore size was $0.124 \pm 0.001 \mathrm{~mm}$, and weft pore size was $0.157 \pm 0.001 \mathrm{~mm}$ (Table 2). The wicking increment is low due to the fabric surface structure, yarn twist and pore dimension of this fabric.

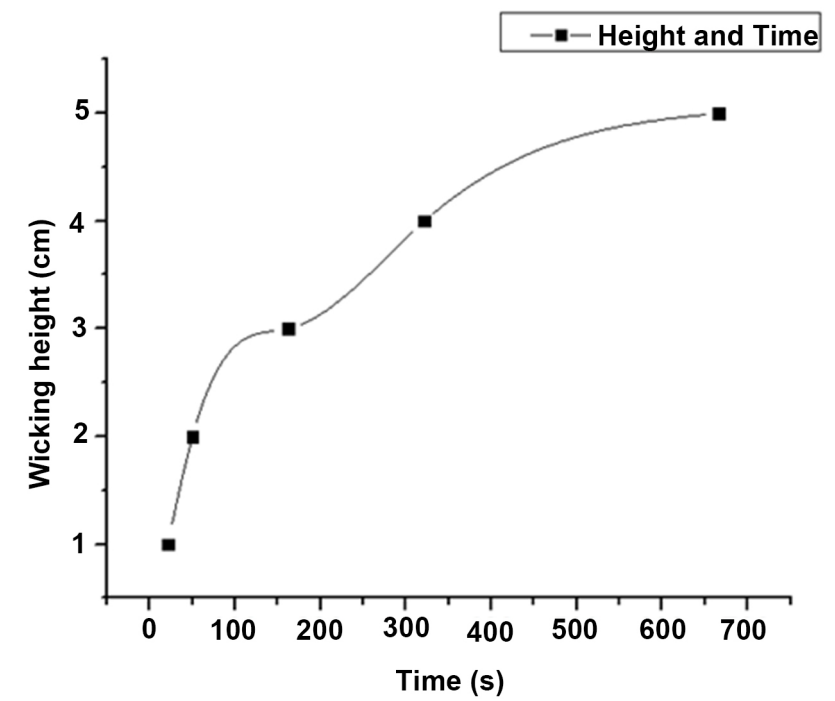

Figure 4. The wicking height of sample B.

In sample B, wicking capacity is better than sample A. Because of this fabric surface construction and the pore size of this fabric, it is little faster to reach the wicking testing distance and hit the test height very easily. Figure 4 shows the time axis is $21 \mathrm{sec}$ then the wicking height axis is $1 \mathrm{~cm}$. Thus, when the time axis is $50,162,322$ and $666 \mathrm{sec}$, then the wicking height axis is $2,3,4$ and $5 \mathrm{~cm}$. The surface construction of sample B looks like straight weaving fabric. In this fabric warp yarn is not twisted and weft yarn is twisted and warp pore size was $0.072 \pm$ $0.001 \mathrm{~mm}$ and weft pore size was $0.158 \pm 0.001 \mathrm{~mm}$ (Table 2). At the beginning the wicking speed is faster but after $3 \mathrm{~cm}$ wicking height the wicking velocity is decreased. Due to the yarn twist, fabric construction and pore size the wicking increment is good.

The wicking performance in sample $\mathrm{C}$ is better than the sample $\mathrm{A}$ and $\mathrm{B}$. Due to its surface construction, yarn twist and the pore size of this fabric, sample C's wicking properties are good. Figure 5 shows the time axis is $21 \mathrm{sec}$ then the wicking height axis is $1 \mathrm{~cm}$. Thus, when the time axis is 56,130, 242 and $537 \mathrm{sec}$, then the wicking height axis is $2,3,4$ and $5 \mathrm{~cm}$. There is no twisted warp yarn in this fabric but weft yarn is twisted. This structure of fabric and yarn is similar to 


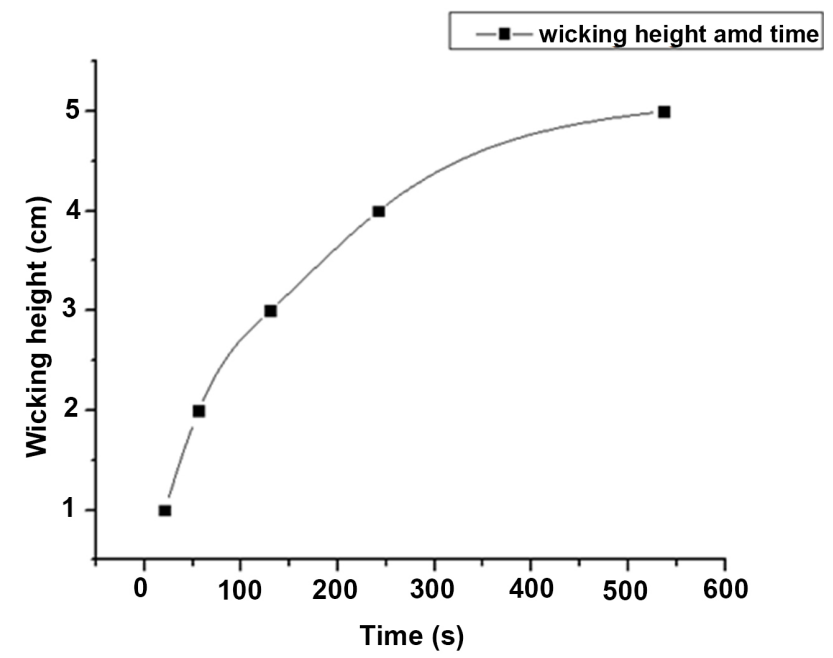

Figure 5. The wicking height of sample C.

sample B. Sample C's warp pore size was $0.070 \pm 0.001 \mathrm{~mm}$ and weft pore size was $0.158 \pm 0.001 \mathrm{~mm}$ (Table 2). The wicking velocity in this sample at the beginning stage is faster than the finishing wicking velocity. The sample C's wicking capability is good above all of this reason.

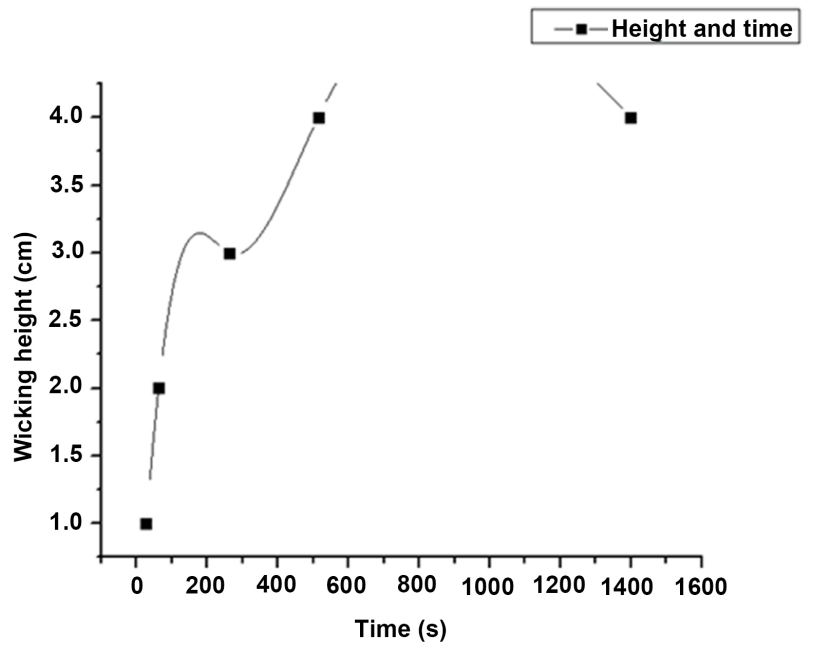

Figure 6. The wicking height of sample D.

In sample $\mathrm{D}$, wicking capacity is poor than $\mathrm{B}, \mathrm{C}$ and $\mathrm{E}$, but this wicking property is slightly better than sample A. Figure 6 shows the time axis is $26 \mathrm{sec}$ then the height axis is $1 \mathrm{~cm}$. Thus, when the time axis is $62,263,514$, and $1400 \mathrm{sec}$, then the wicking height axis is 2, 3, 4 and $4 \mathrm{~cm}$. The liquid passes slowly in this sample and finally the wicking has stopped when the test height reached $4 \mathrm{~cm}$. Sample D's surface constructions looks like little bit tight from A, B, C and warp and weft yarn both are twisted. In this sample, at the beginning stage the wicking velocity is good and this fabric is capable to reach of $4 \mathrm{~cm}$ height. The wicking is completely stopped after $4 \mathrm{~cm}$ of wicking height. In this fabric warp and weft 
pore sizes were $0.120 \pm 0.001 \mathrm{~mm}$ and $0.132 \pm 0.001 \mathrm{~mm}$ (Table 2). This wicking capability of the fabric is poor than sample B, C, E but it has good wicking capability from sample A.

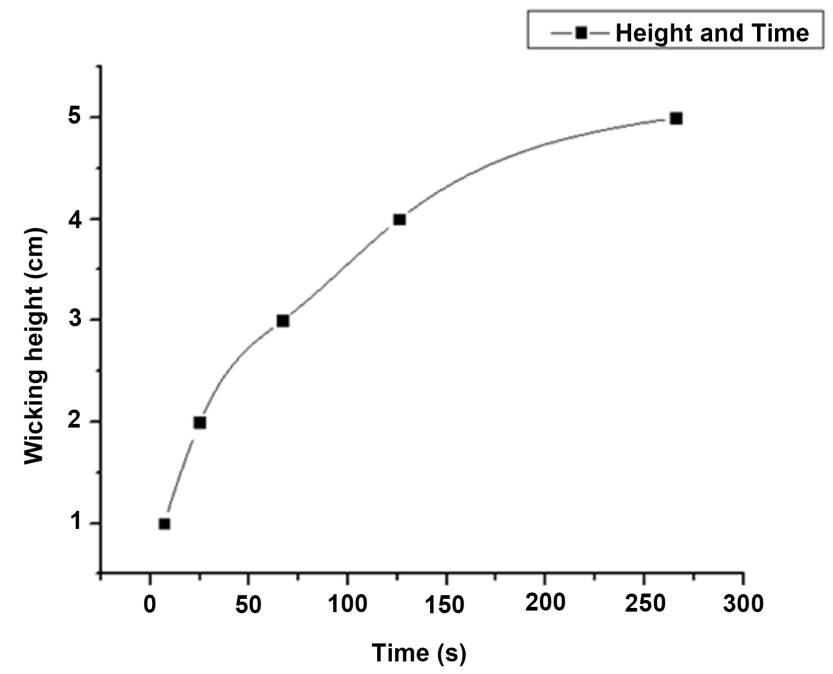

Figure 7. The wicking height of sample E.

In sample $\mathrm{E}$, the wicking performance is better than the entire sample $\mathrm{A}, \mathrm{B}, \mathrm{C}$ and D. This surface morphology of the fabric is different from other samples. The surface construction of the sample E looks very tight and the warp yarn covers the yarn of the weft and it has good pore size. Figure 7 shows the time axis is $7 \mathrm{sec}$ then the wicking height axis is $1 \mathrm{~cm}$. Thus, when the time axis is 25, 67,126 , and $266 \mathrm{sec}$, then the wicking height axis is $2,3,4$ and $5 \mathrm{~cm}$. In this sample warp and weft yarn both are twisted. Both warp and weft yarn is twisted in this sample. Sample E’s warp pore size was $0.024 \pm 0.001 \mathrm{~mm}$ and weft pore size was $0.126 \pm 0.001 \mathrm{~mm}$ (Table 2). This sample of fabric absorbed the liquid very quickly. It has a good wicking capacity in this sample and wicking testing time is less from other sample testing time. The wicking speed is much faster from the beginning to the end. The wicking increase is higher because of the yarn twist, fabric construction, and pore size.

\subsection{Relation of Wicking Height and Wicking Time}

In general, the expression of the rate of liquid capillary increase in porous media is in Hagen-poiseuille's law,

$$
\frac{\mathrm{d} h}{\mathrm{~d} t}=\frac{R_{D}^{2}}{8_{n}} \cdot \frac{\nabla P}{h}
$$

In this law, $h$ is the height which the water arrives at the time $t, R_{D}$ is the mean hydrodynamic radius of pores, $\eta$ is the water's viscosity, and $\Delta p$ is the difference in pressure. Use to calculate the vertical wicking with a gravitational influence [19]. 


$$
\Delta P=\frac{2 \gamma \cos \theta}{R_{s}}-\rho g h
$$

Here, the surface tension and density of the liquid, the advancing contact angle of the liquid on the solid, the acceleration due to gravity, and $R_{S}$ is the mean static radius of pores. Replacing Equation (2) with Equation (1), the vertical wicking equation becomes as follows.

$$
\frac{\mathrm{d} h}{\mathrm{~d} t}=\frac{R_{D}^{2}}{8 n h} \cdot\left(\frac{2 \gamma \cos \theta}{R_{\mathrm{s}}}-\rho g h\right)
$$

The hydrostatic pressure in Equation (2) can be neglected in the early stages of the process and Equation (1) yields the Lucas-Washburn equation by integration.

$$
h^{2}=\frac{R_{D}^{2} \gamma \cos \theta}{R_{s} 2 n} \cdot t
$$

Or,

$$
h^{2}=A+t
$$

Wicking percentage $(\%)$

$=\frac{\text { Sample weight after wicking }- \text { Sample weight before wicking }}{\text { Sample weight before wicking }} \times 100 \%$

$$
\Delta p=\frac{\Delta S_{2}-\Delta S_{1}}{\Delta S_{1}} \cdot 100 \%
$$

Here, $\Delta p$ is the wicking percentage, $\Delta S_{2}$ is the sample weight after wicking, $\Delta S_{1}$ is the sample weight before wicking and it has multiplied by 100 .

$$
\begin{gathered}
\text { Velocity }=\frac{\text { diplacement }}{\text { time }} \\
V=\frac{\Delta d}{\Delta t}
\end{gathered}
$$

In here, $\Delta d$ is the displacement $\Delta t$ is the time and $V$ is the velocity. The units of this value $\mathrm{cm} / \mathrm{s}$.

Based on Formula 5, the wicking height is proportional to the time (Figure 8). In addition, the experimental results from this work showed that the wicking height had a positive and high correlation with time, indicating that the $\mathrm{Lu}$ cas-Washburn equation was appropriate to evaluate the wicking property of fabrics due to the compact structure of the silk fabric.

Different fabrics have different wicking performance ability. At the beginning the wicking rate in weft direction was slightly faster than the warp direction, which may be due to the following reasons: 1) a higher number of yarns were in the weft direction in the fabric, and the yarns were responsible for the main part of the wicking action in the fabrics [13] [19]. The capillary elevation in the weft direction was therefore more remarkable; 2 ) the spaces between weft yarns were smaller than those between warp yarns, resulting in a smaller forward contact angle of the liquid on the yarn, whereby the capillary elevation in the weft direction was faster. In experiments, Babu [23] also observed the same phenomenon and stated that the tension could be one reason. 


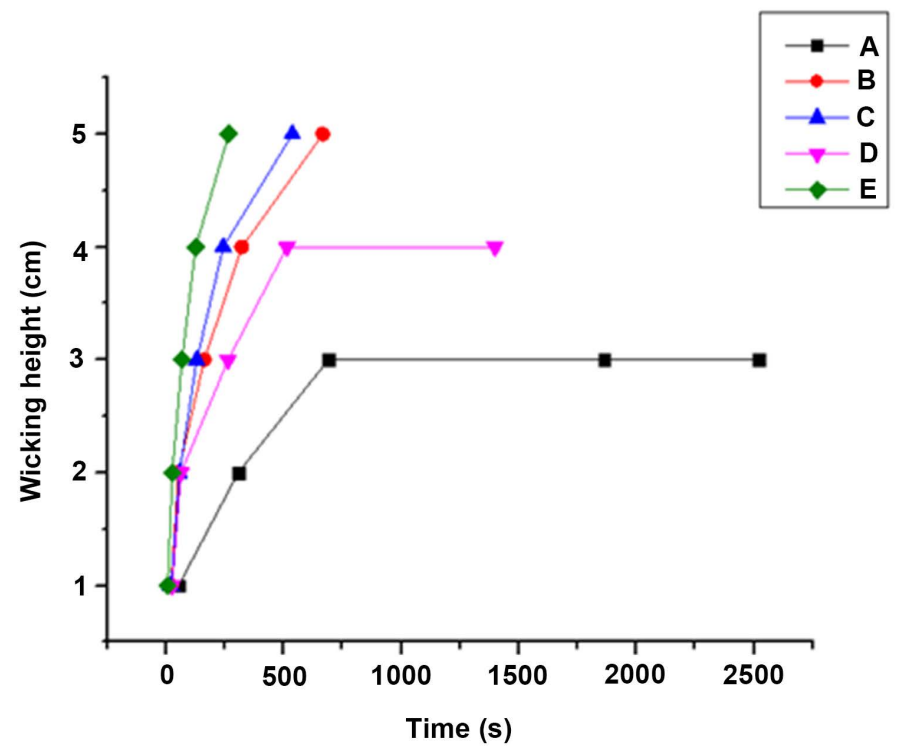

Figure 8. Wicking height vs. time.

\subsection{The Rate of Wicking in Various Directions}

While the wicking rate can be obtained from the equation of Lucas-Washburn, it is a particular overview of the whole method of wicking. Coefficient A (in Equation (5)), on the other hand, is not a constant. Thus the entire wicking process was split into tiny wicking height/time periods to comprehend more comprehensive wicking process data.

Using equation, where $v w$ is the speed of water rising in the fabric, $s$ the height of the wicking, and $t$ is the time; the wicking rate can be achieved. Figure 9 shows

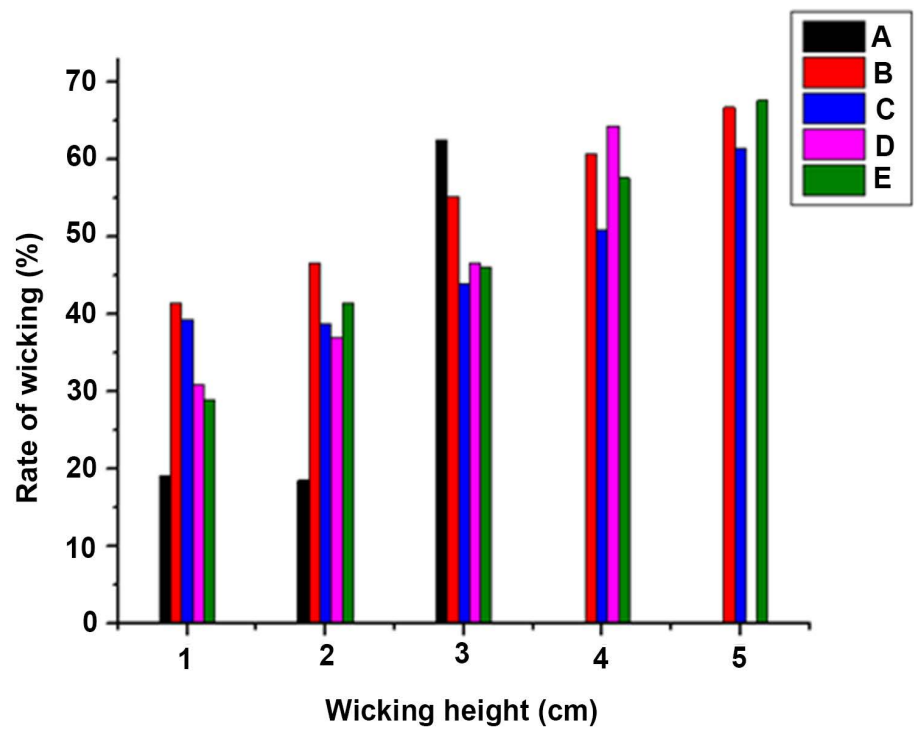

Figure 9. Rate of wicking vs. wicking height.

the wicking rates of silk fabric. The wicking levels reduced with a rise in height at every $1 \mathrm{~cm}$ range. The reason for this occurrence could be due to the distinct 
fluid volume variability in each centimeter range, which could be another internal driving power for water. The nearer the tank, the higher would be the distinction in fluid density. In addition, the wicking rate in the direction of the weft was higher than in the warp, especially at the start of the wicking process. The factors may be as follows: 1) More fibers and yarns in the weft direction than in the warp resulting in more channels and greater capillary power in the weft path at the original level; 2) After the fabric had absorbed water, the water would be spread equally to all yarns [18], and then the distinction in the wicking rate in both directions becomes lower.

\subsection{Mass of Fluid Absorbed Rise vs. Height of Wicking}

An important parameter for understanding the wicking mechanism is also the increase in mass caused by absorbed water. Obviously, the general volume of fluid consumed by the material improved with a rise in wicking height and the boost in weight per centimeter interval decreased with a rise in wicking height, suggesting that the gradient of mass rise reduced at each $1 \mathrm{~cm}$ interval. The reason may be due to the gravity impact and hygroscopicity of the fiber. Meanwhile, the increase in weft and warp direction volume had a tiny distinction and alternate dominance (Figure 10), which may be due to the amount of yarns and the time impact. The wicking was more effective in the direction of the weft. In addition, water in the fabric spread equally across all branches; therefore the differences in mass increments between the direction of the warp and the direction of the weft were smaller.

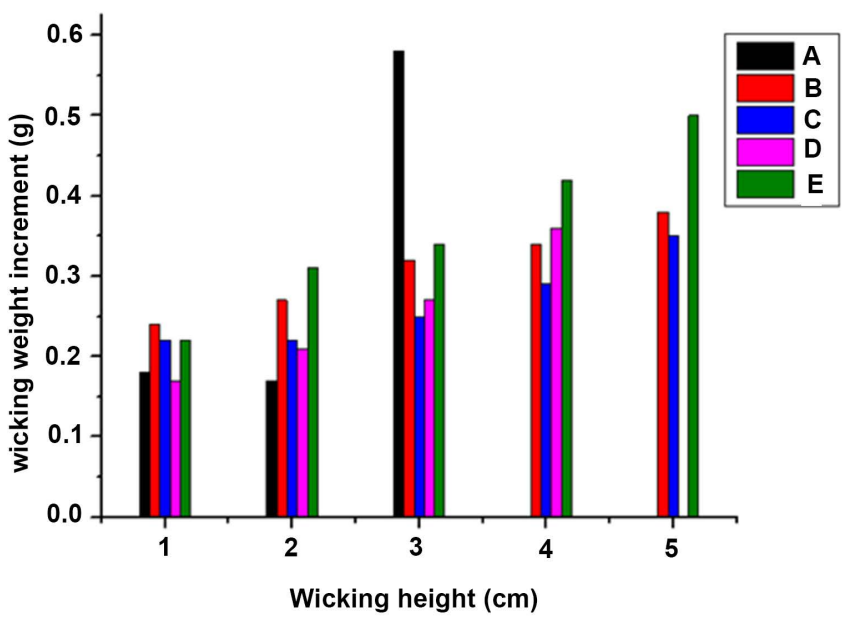

Figure 10. Wicking weight increment vs. wicking height.

\subsection{Mass Increase in the Absorbed Liquid vs. Time}

In the beginning, the wicking rate in the weft direction was slightly faster than in the warp, but the mass increase corresponding to time was almost the same in the first 30 - 120 seconds, showing a significant difference in the water absorption capacity of the silk fabric (Figure 11). In this figure, the mass increase of a few samples and the wicking time is good. Increment of sample E and sample $\mathrm{C}$ 
mass is better from others and it took less time to reach the test distance. Sample A's mass increase is also good, but it took a long time and the wicking had totally stopped after $3 \mathrm{~cm}$ wicking height.

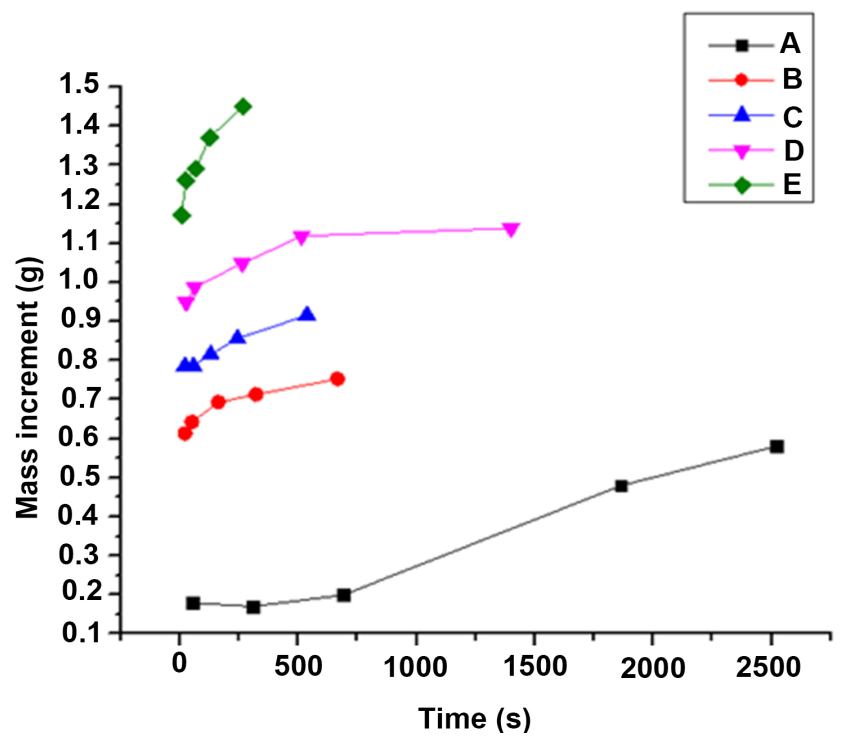

Figure 11. Wicking mass increment vs. wicking time.

\subsection{Durative Wicking Height after Removal of the Liquid Reservoir}

The durative wicking height was created after the removal of the wicking liquid reservoir to explore the effect of silk fabric fiber/yarn hygroscopicity on the wicking property The length of the wicking height was the distinction between the initial wicking height and the height after removal of the wicking liquid reservoir; the comparative height increase $H I_{R i}$ is provided by,

$$
H I_{R i}=H_{f i}-H_{w i}-H a_{i-1}
$$

where $H_{f i}$ is the ultimate wicking height after separating the fabric from water at an $1 \mathrm{~cm}$ wicking height, $H_{w i}$ is the wicking height when separating the fabric from water, and $H a_{i-1}$ is the complete wicking height after separating the fabric from water at a wicking height of $(i-1) \mathrm{cm}$.

The length rise in height was important when the reservoir was separated from the fabric at a wicking height of $1 \mathrm{~cm}, 2 \mathrm{~cm}, 3 \mathrm{~cm}$ and $4 \mathrm{~cm}$ but the sample-A had completely stopped after $3 \mathrm{~cm}$ wicking (Figure 12). It disclosed that the quantity of water intake in the fabric was near to saturation at $1 \mathrm{~cm}, 2 \mathrm{~cm}, 3 \mathrm{~cm}$ and $4 \mathrm{~cm}$ during the wicking phase. Furthermore, an exciting occurrence was that the comparative height rises were reduced when the fabrics were taken from the water at a wicking height of $4 \mathrm{~cm}$ and $5 \mathrm{~cm}$ compared to a wicking height of $1 \mathrm{~cm}, 2 \mathrm{~cm}$ and $3 \mathrm{~cm}$. The causes could be as follows: 1) the gravitational effect at greater wicking heights the gravitational impact is greater, thus decreasing water intake; 2) the water mass at distinct height areas; the water volume per centimeter was inversely equal to the wicking height (Figure 10). 


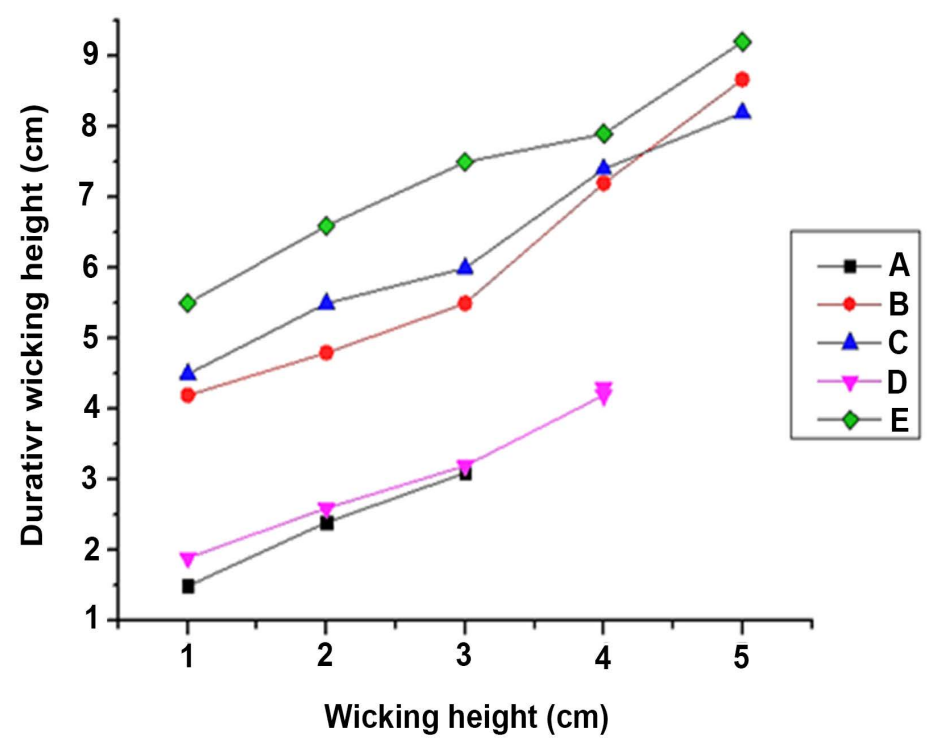

Figure 12. Durative wicking height vs. wicking height.

\subsection{Relation between Wicking Velocity and Wicking Height}

Here at the beginning the wicking velocity is high, when the sample wicking height is $1 \mathrm{~cm}$. Figure 13 are shows the relationship between wicking velocity increment and wicking height increment. The sample wicking velocity decreased when the sample wicking height is increased respectively. This figure also demonstrates that sample A's wicking height is $3 \mathrm{~cm}$ and the sample D's wicking height is $4 \mathrm{~cm}$ but at the beginning sample A's wicking speed is greater than sample D's. In this figure we can see the wicking velocity of sample E, C, and B is good, but the wicking speed of sample $\mathrm{E}$ is better compared from others.

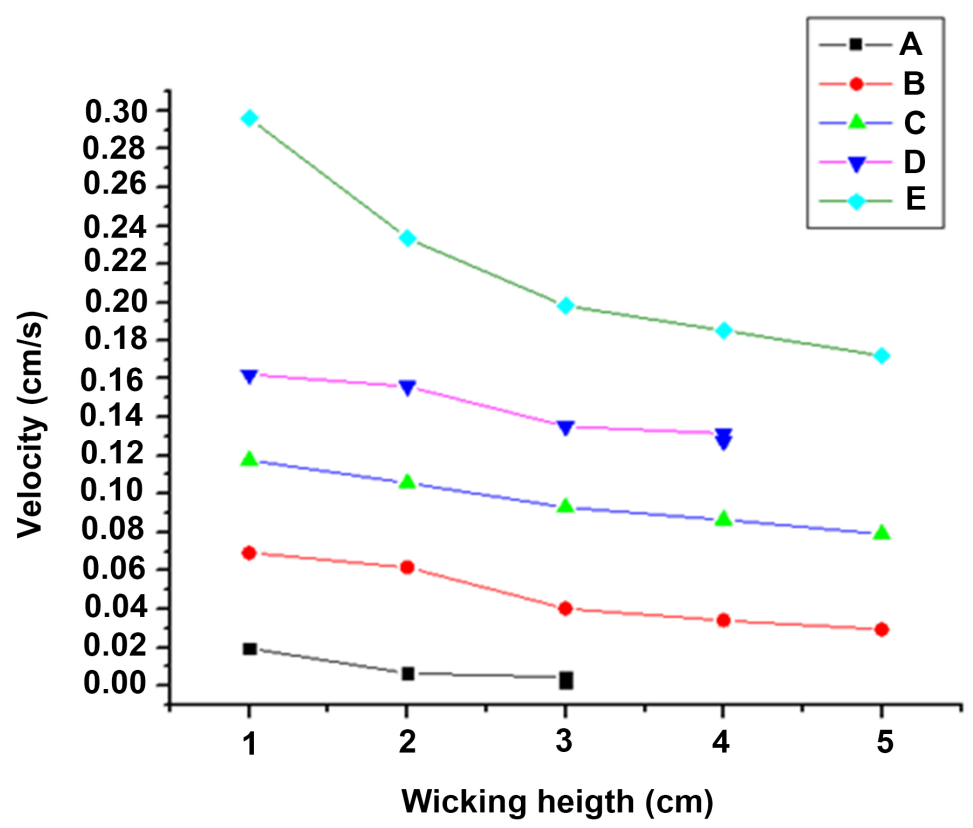

Figure 13. Wicking velocity vs. wicking height. 


\subsection{Relation between Mass Increment and Wicking Velocity}

Figure 14 represents the wicking mass increase of the sample per $1 \mathrm{~cm}$ and the increase in wicking speed outcomes of that test. Here the increase in sample E's wicking height and the wicking velocity is large from other samples. Sample A's mass increase is good, but its velocity is poor at the finish. Sample B's and D's wicking mass and velocity look the same but sample C's wicking mass and velocity is slightly different from $B$ and $D$. The increase in sample $C$ mass and velocity is better from A, B and C. Every sample gets high wicking speed when the taste period started and gradually the speed has decreased. At the last moment the sample A's weight increased but the velocity has increased. So, the best sample in this figure is sample E. Cause its velocity and mass increase from the beginning stage to the end stage is better from other samples.

We can understand the hydrophobic capacity in this silk fabric by contact angle testing. The contact angle results of these five samples were shown in Table 3 . Sample D has high contact angle, indicating that this sample has a good hydrophobic capacity and lowest contact angle content sample C, which means this sample has less hydrophobic capacity (Figure 15). Another thing, we can also

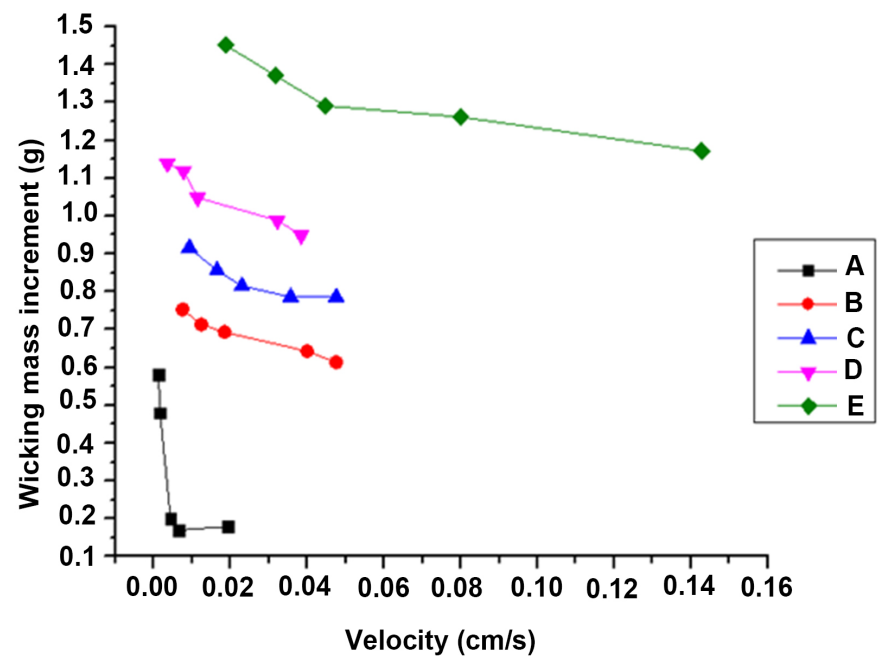

Figure 14. Wicking mass increment vs. Wicking velocity.

Table 3. Contact angle test results of the silk fabric.

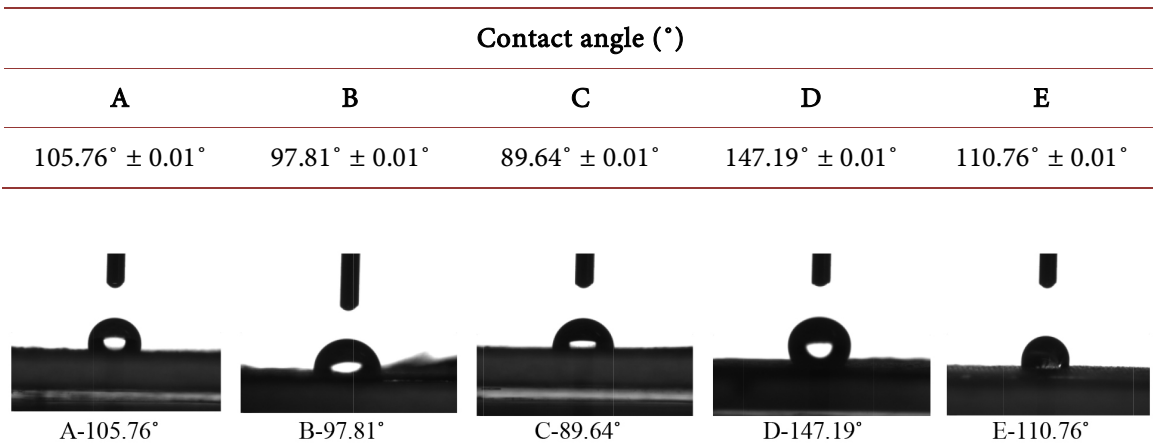

Figure 15. Contact angle of the samples. 
understand the absorption performance of this sample fabric through contact angle testing. Here the same $\mathrm{E}$ absorbs the water very quickly from the other sample.

\section{Conclusion}

In this paper, the wicking properties of woven silk fabrics have been investigated. This work has been done to understand the silk fabric of wicking behavior by measuring the wicking height, rate, velocity and durative wicking height of this fabric. For evaluating the wicking behavior of silk fabrics, the Lucas-Washburn equation was appropriate. The wicking speed was same in both directions but the weft direction wicking height and velocity was significantly quicker at the beginning of the wicking phase. The increase in mass absorbed per centimeter of silk fabric was inversely proportional to the wicking height. The mass of absorbed liquid in the silk fabrics had no significant difference in both weft and warp directions, but at the beginning the weft direction absorbed the liquid more. It has also been shown how quickly this silk cloth absorbs the sweat from the human body and is capable of absorbing or not being able to absorb the entire sweat from the human body and transfer the sweat outside very easily or not. In this test, the silk fabric showed adverse correlation between wicking height and wicking velocity. When the wicking height of the fabric improved, the wicking velocity reduced. Wicking height, wicking rate and velocity showed significant variation because it depends on the structure of the fabric surface. This test fabric had different density, yarn twist, and surface design, for that reason the findings of wicking height and speed differed. We can understand from this study that, silk fabric has excellent wicking height, wicking rate, wicking speed, and durative wicking height. At the end of this research it indicates that silk fabric has good wicking properties, but sometimes the wicking performance depends on the fabric surface construction and yarn twist.

\section{Conflicts of Interest}

The authors declare no conflicts of interest regarding the publication of this paper.

\section{References}

[1] Crow, R.M. and Dewar, M.M. (1993) The Vertical and Horizontal Wicking of Water in Fabrics (U). Ottawa.

[2] Sakib, N. and Zhu, G. (2019) Experimental Investigation to Evaluate Critical Aspects of Denim Quality. IOSR Journal of Polymer and Textile Engineering, 6, 50-55.

[3] Jia, T., Wang, Y., Dou, Y., Li, Y., de Andrade, M.J., Wang, R., Fang, S., Li, J., Yu, Z., Qiao, R., Liu, Z., Cheng, Y., Su, Y., Jolandan, M.M., Baughman, R.H., Qian, D. and Liu, Z. (2019) Moisture Sensitive Smart Yarns and Textiles from Self-Balanced Silk Fiber Muscles. Advanced Functional Materials, 29, Article ID: 1808241. https://doi.org/10.1002/adfm.201808241

[4] Xu, R.-C., Zhang, Y.-P. and Zhai, Y.-L. (2004) Study on the Comfortability of Mois- 
ture Transmission and Liberation of the Silk-Like Knitwear of Ultra-Fine Polyester. Journal of Zhongyuan Institute of Technology, 15, 13-15.

[5] Raja, D., Koushik, C.V., Ramakrishnan, G., Subramaniam, V. and Ramesh Babu, V. (2012) Measuring in-Plane Liquid Spread in Fabric Using an Embedded Image Processing Technique. Fibres \& Textiles in Eastern Europe, 20, 72-76.

[6] Bivainyte, A. and Mikucioniene, D. (2011) Investigation on the Dynamic Water Absorption of Double-Layered Weft Knitted Fabrics. Fibres \& Textiles in Eastern Europe, 19, 64-70.

[7] Bivainyte, A. and Mikucioniene, D. (2011) Investigation on the Air and Water Vapour Permeability of Double-Layered Weft Knitted Fabrics. Fibres \& Textiles in Eastern Europe, 19, 69-73.

[8] Zhu, G., Militky, J., Wang, Y., Sundarlal, B.V. and Kremenakova, D. (2015) Study on the Wicking Property of Cotton Fabric. Fibres \& Textiles in Eastern Europe, 23, 137-140.

[9] Harnett, P.R. and Mehta, P.N. (1984) A Survey and Comparison of Laboratory Test Methods for Measuring Wicking. Textile Research Journal, 54, 471-478. https://doi.org/10.1177/004051758405400710

[10] Lucas, R. (1918) Ueber das zeitgesetz des kapillaren aufstiegs von flussigkeiten. Kolloid-Zeitschrift, 23, 15-22. https://doi.org/10.1007/BF01461107

[11] Washburn, E.W. (1921) The Dynamics of Capillary Flow. Physical Review Journals Archive, 17, 273-283. https://doi.org/10.1103/PhysRev.17.273

[12] Perwuelz, A., Mondon, P. and Caze, C. (2000) Experimental Study of Capillary Flow in Yarns. Textile Research Journal, 70, 333-339. https://doi.org/10.1177/004051750007000409

[13] Liu, T., Choi, K.F. and Li, Y. (2008) Wicking in Twisted Yarns. Journal of Colloid and Interface Science, 318, 134-139. https://doi.org/10.1016/j.jcis.2007.10.023

[14] Wang, N., Zha, A.X. and Wang, J.X. (2008) Study on the Wicking Property of Polyester Filament Yarns. Fibers and Polymers, 9, 97-100. https://doi.org/10.1007/s12221-008-0016-2

[15] Fan, F. and Qi, H.J. (2007) Relationship between Capillary Properties and Configurations and Wicking Capability of Fabric. Journal of Textile Research, 28, 38-41.

[16] Mazloumpour, M., Rahmani, F., Ansari, N., Nosrati, H. and Rezaei, A.H. (2011) Study of Wicking Behavior of Water on Woven Fabric Using Magnetic Induction Technique. The Journal of the Textile Institute, 102, 559-567. https://doi.org/10.1080/00405000902952200

[17] Rajagopalan, D., Aneja, A.P. and Marchal, J.M. (2001) Modeling Capillary Flow in Complex Geometries. Textile Research Journal, 71, 813-821. https://doi.org/10.1177/004051750107100911

[18] Minor, F.M. and Schwartz, A.M. (1960) Pathways of Capillary Migration of Liquids in Textile Assemblies. American Dyestuff Reporter, 49, 37-42.

[19] Hollies, N.R.S., Kaessinger, M.M., Watson, B.S. and Bogaty, H. (1957) Water Transport Mechanisms in Textiles Materials. Part II: Capillary-Type Penetration in Yarns and Fabrics. Textile Research Journal, 27, 8-13. https://doi.org/10.1177/004051755702700102

[20] Saricam, C. and Kalaoglu, F. (2014) Investigation of the Wicking and Drying Behaviour of Polyester Woven Fabrics. Fibres \& Textiles in Eastern Europe, 22, 73-78.

[21] Hamraoui, A. and Nylander, T. (2002) Analytical Approach for the Lucas-Washburn Equation. Journal of Colloid and Interface Science, 250, 415-421. 
https://doi.org/10.1006/jcis.2002.8288

[22] Minor, F.W., Schwartz, A.M., Wulkow, E.A. and Buckles, L.C. (1959) The Migration of Liquids in Textile Assemblies, Part II: The Wicking of Liquids in Yarns. TeXtile Research Journal, 29, 931-939. https://doi.org/10.1177/004051755902901201

[23] Babu, V.R., Koushik, C.V., Lakshmikantha, C.B. and Subramaniam, V. (2011) Influence of the Weave Factor on the Character of Fabric Wicking Measured by a Multiple Probe Vertical Wicking Tester. Fibres \& Textiles in Eastern Europe, 19, 60-63. 